\title{
Left atrial longitudinal strain by speckle tracking as independent predictor of recurrence after electrical cardioversion in persistent and long standing persistent non-valvular atrial fibrillation
}

\author{
Luis Antonio Moreno-Ruiz ${ }^{1}$ [ $\cdot$ Alejandra Madrid-Miller ${ }^{2} \cdot$ Jerónimo Enrique Martínez-Flores $^{3}$. \\ Jesús Antonio González-Hermosillo ${ }^{4}$. Jorge Arenas-Fonseca ${ }^{5} \cdot$ Noé Zamorano-Velázquez $^{5}$ - Beatriz Mendoza-Pérez ${ }^{1}$
}

Received: 10 February 2019 / Accepted: 3 April 2019 / Published online: 16 April 2019

(c) The Author(s) 2019

\begin{abstract}
Atrial fibrillation (AF) is the most common arrhythmia in humans. After successful cardioversion, there is a recurrence of $60 \%$ due to atrial remodeling, and it has been shown that the global peak atrial longitudinal strain (GPALS) is decreased in these subjects. The aim of this study was to evaluate the predictive value of GPALS for AF recurrence. A prospective cohort of patients with persistent (PnVAF) and long standing persistent non-valvular AF (LSPnVAF) which underwent electrical cardioversion was evaluated with standard echocardiographic variables and GPALS quantification. The primary endpoint was AF recurrence at 6 months. We included PnVAF ( $n=50$, aged $68.4 \pm 10.2$ years, female $46 \%$, lasted AF 6 months) and $\operatorname{LSPnVAF}(\mathrm{n}=81$, aged $66.5 \pm 13.1$ years, female $36 \%$, lasted AF 18 months). At 6 months there were a $68 \%$ of recurrence of AF in PnVAF and 53\% in LSPnVAF group. GPALS was lower in recurrence $7.8 \pm 2.0 \%$ versus $21.2 \pm 8.9 \%(\mathrm{p}<0.001)$ for PnVAF and $7.3 \pm 2.7 \%$ versus $20.7 \pm 7.6 \%$ ( $\mathrm{p}<0.001)$ in LSPnVAF. GPALS $\leq 10.75 \%$ discriminates recurrence at 6 months with a sensitivity of $85 \%$, specificity $99 \%$, PPV $85 \%$, NPV $90 \%$, LR +8.5 and LR- 0.17 . The independent predictors of recurrence in PnVAF were GPALS $\leq 10.75 \%$ HR 8.89 [(2.2-35.7), $\mathrm{p}<0.01]$ meanwhile in LSPnVAF were age HR 1.039 [(1.007-1.071), $\mathrm{p}=0.01]$, and GPALS $\leq 10.75 \%$ HR 28.1 [(7.2-109.1), $\mathrm{p}<0.001]$. In subjects with PnVAF and LSPnVAF with successful electrical cardioversion, GPALS $\leq 10.75 \%$ predicts arrhythmia recurrence at 6-month follow-up.
\end{abstract}

Keywords Atrial fibrillation $\cdot$ Longitudinal atrial strain $\cdot$ Recurrence

Luis Antonio Moreno-Ruiz

luismorenomd@hotmail.com

1 Division of Cardiology, UMAE Hospital de Cardiología, Centro Médico Nacional Siglo XXI, IMSS, 330 Cuauhtémoc Av, Doctores, Cuauhtémoc, 06720 Mexico City, Mexico

2 Direction of Education and Research, UMAE Hospital de Cardiología, Centro Médico Nacional Siglo XXI, IMSS, 330 Cuauhtémoc Av, Doctores, Cuauhtémoc, 06720 Mexico City, Mexico

3 Department of Electrophysiology, UMAE Hospital de Cardiología, Centro Médico Nacional Siglo XXI, IMSS, 330 Cuauhtémoc Av, Doctores, Cuauhtémoc, 06720 Mexico City, Mexico

4 Medical Subadrees of Innovation and Development Project, Instituto Nacional de Cardiología "Ignacio Chávez", 1 Juan Badiano, Sección XVI, Tlalpan, 14080 Mexico City, Mexico

5 Department of Echocardiography, UMAE Hospital de Cardiología, Centro Médico Nacional Siglo XXI, IMSS, 330 Cuauhtémoc Av, Doctores, Cuauhtémoc, 06720 Mexico City, Mexico

\section{Introduction}

Atrial fibrillation (AF) is the most frequent sustained arrhythmia in humans, and it is highly relevant due to the impact of the complications it produces. It can be treated by controlling the rhythm or the frequency [1-10]. Cardioversion is widely recommended for symptomatic subjects, even when receiving optimal treatment, and restores the physiological conditions of the atrium [8-14]. Recurrence after cardioversion reaches up to $60 \%$ in the first 12 months, a fact that has been associated to atrial remodeling [15-22]. Several authors consider the following as predictors of recurrence: age, use of angiotensin-converting enzyme inhibitors (ACE inhibitors), angiotensin II receptor blockers (ARBs), spironolactone, comorbidities, time of evolution of AF, increased diameter and atrial volumes, and low peak velocity of the left atrial appendage, among others [23-33]. Echocardiographic techniques as speckle tracking permit evaluate the structure and the function at a finer level thanks to the 
measuring of myocardial fiber deformation [34-40]; this technique allows measuring the global peak atrial longitudinal strain (GPALS), which decreases in subjects with AF and holds an inverse correlation with the degree of fibrosis measured by magnetic resonance and histology [41-44]. The aim of this study was to evaluate the predictive value of the GPALS in the discrimination of post-cardioversion arrhythmia recurrence in subjects with persistent non-valvular atrial fibrillation (PnVAF) and long standing persistent non-valvular AF (LSPnVAF).

\section{Materials and methods}

From June 2015 to January 2018, we recruited subjects with PnVAF (AF that lasts longer than 7 days, including episodes that are terminated by cardioversion, either with drugs or by direct current cardioversion, after 7 days or more) and LSPnVAF (continuous AF lasting for $\geq 1$ year when it is decided to adopt a rhythm control strategy) eligible for elective electrical cardioversion, at the Hospital de Cardiología, CMN Siglo XXI. The non-inclusion criteria were: pregnancy, ischemic disease, cardiomyopathy, congenital heart diseases, pulmonary artery systolic pressure (PASP) $>60 \mathrm{mmHg}$ or left ventricular ejection fraction (LVEF) < $50 \%$, need for emergency electrical cardioversion, previous cardioversion performed less than 6 months before, presence of single or dual-chamber pacemaker and average ventricular response $>110$ beats per minute (bpm) or $<40 \mathrm{bpm}$. Four subjects were excluded due to poor echocardiography window and the inability to quantify the GPALS using QLAB software (Philips). The two-dimensional echocardiograms in DICOM format were analyzed to quantify the GPALS in 131 subjects. We also analyzed the demographic and echocardiographic conventional data, both transthoracic and transesophageal. All the subjects signed written informed consents to use the documentary studies and for clinical and phone follow-up. The study protocol was authorized for its implementation by the Local Research and Health Research Ethics Committee.

During the visit previous to cardioversion, demographic, clinical and anthropometric data were collected. The classification of type of AF was conducted by a trained electrophysiologist according to the interview and electrocardiographic evidence. The electrical cardioversion was carried out by the treating cardiologist, having ensured three previous weeks of optimal anticoagulation and no evidence of thrombus by transesophageal echocardiogram on the same day the procedure took place. We considered the cardioversion successful after the termination of AF was confirmed by the presence of organized atrial activity and criteria of normal sinus rhythm. All the subjects received $150 \mathrm{mg}$ propafenone TID and metoprolol BID at titrated dose as maintenance treatment. The subjects were given clinical follow-up during the first four weeks; afterwards, the follow-up took place once a month including clinical and electrocardiographic assessment for 6 months. A Holter monitoring test was performed after one and 6 months or before in case the subject showed palpitations, collapse, dyspnea or thoracic pain in order to find AF recurrence. The presence of two or more episodes of irregular atrial activity lasting at least $10 \mathrm{~min}$ documented by Holter monitoring or ECG was considered recurrence after a successful cardioversion. Two researchers, a cardiologist and an electrophysiologist, with independent blinded quality, verified these episodes.

All the transthoracic echocardiography studies were conducted placing the subject lying down on the back or left side, using a Philips iE33 commercial ultrasound system with S5-1 multi frequency transducer, following the recommendations provided by the American Society of Echocardiography. We obtained standard two-dimensional images of the cardiac chambers, valves and great vessels from the parasternal and apical long axes (4, 2 and 3 chambers) with a speed of 80-100 frames per second, including three beats per registry and simultaneous electrocardiography monitoring. We measured the length and volume of both atria and aortic annulus after systole, while the aortic root and dimensions and parietal width of both ventricles were measured at the end of ventricular diastole. We calculated the ejection fraction by modified Simpson's method, shortening fraction and final systolic and diastolic ventricular volumes. From the apical four-chamber view, we obtained the spectral registry of the mitral inflow pattern using pulsed Doppler. We measured the early diastolic filling velocity (E-wave), its deceleration (DT), and the isovolumic relaxation time (IVRT). In addition, we obtained the velocity of e' and S using pulsed Doppler to calculate the E/e' ratio, after calculating the average of the values from the mitral septal-lateral annulus. We determined the area of the atria in systole from the four-chamber view. In order to determine the atrial volumes, we applied the area-length method in views of four and two chambers in systole. Once they were averaged, they were indexed to the body surface (Mosteller formula). We registered apical views of four and two chambers in sequences of three beats each for outboard analysis. We took the velocity of the left appendage with pulsed Doppler from the transesophageal echocardiogram performed during the usual assessment protocol using an S7-2 omni probe (Philips). The GPALS outboard analysis was done using QLAB Advanced Quantification Software version 8.1 (Philips) with two-dimensional speckle tracking by two independent and blinded echocardiographers. The GPALS calculation was done tracing the atrial endocardial border while its automated determination was completed using QLAB (Philips) in the apical views of four and two chambers (Fig. 1), with an average of three beats each; we 

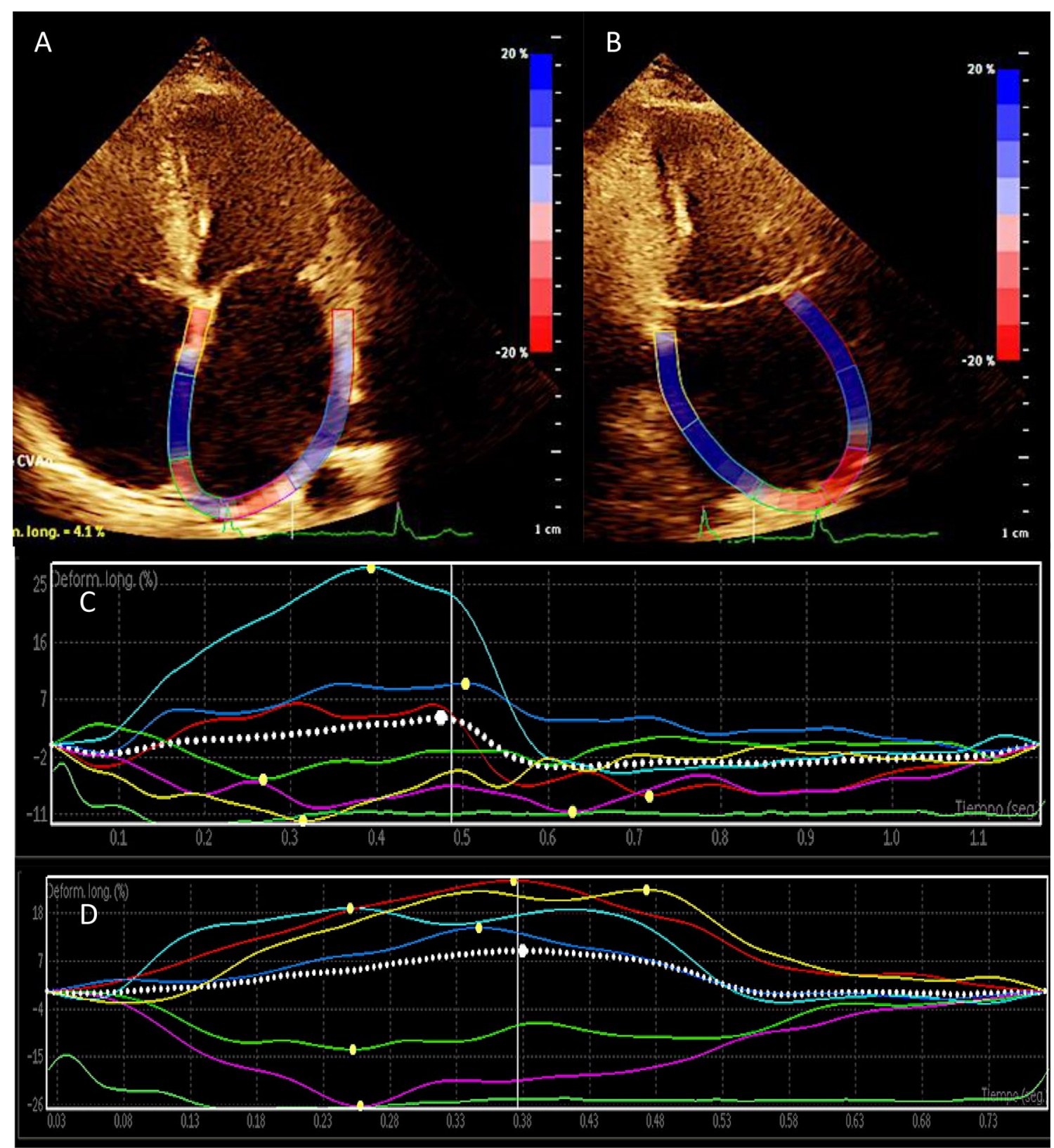

Fig. 1 Representative global peak atrial longitudinal strain (GPALS) images. Apical long axes of four (a) and two chambers (b) with tracing the atrial endocardial border. Automated GPALS quantification with two-dimensional speckle tracking in apical views of four (c) and two chambers (d). We defined GPALS as the average of three beats each, in this case GPALS was $6.8 \%$ in a subject with AF recurrence. $G P A L S$ global peak atrial longitudinal strain, $A F$ atrial fibrillation

and range) while the qualitative ones were expressed as frequencies and percentages. We used Student's t test or the $U$ Mann-Whitney test according to the distribution for differences between groups of quantitative variables and Chi squared distribution for groups of qualitative variables. We assessed reproducibility by selecting ten random echocardiographic studies that were recorded as raw data for intra and interobserver variability. Observers were blinded; for intraobserver variability, the same observer evaluated raw 
echocardiographic data 1 month after the first evaluation. We performed a receiver-operating characteristic (ROC) curve to determine the cut-point of GPALS associated to recurrence. We calculated sensitivity, specificity, predictive values and the likelihood ration for the calculated cut-point. A multivariate Cox proportional hazards regression analysis was conducted to evaluate the effect of the potentially confounding variables, event-free (recurrence) survival curve and calculation of adjusted HR. The variables associated to recurrence $\mathrm{p}<0.20$ were introduced to the model; a value $p \leq 0.05$ was considered significant. The statistical analysis was carried out using SPSS Statistics V21.0 (IBM Corporation).

\section{Results}

The study sample included 50 subjects with PnVAF (aged $68.4 \pm 10.2$ years, female $46 \%$, lasted AF 6 months) and 81 with LSPnVAF (aged $66.5 \pm 13.1$ years, female $36 \%$, lasted AF 18 months). Baseline and demographic characteristics are summarized in Table 1.
At 6 months, the subjects with PnVAF showed 68\% (n $=34)$ of recurrence after cardioversion versus $53 \%(\mathrm{n}=$ 43 ) among the subjects with LSPnVAF $(p=n s)$. The latter group showed earlier recurrence ( 14 vs. 30 days; $p=$ 0.04). The analysis in the PnVAF group showed higher body weight among subjects with AF recurrence than those in sinus rhythm $(75.5 \pm 10.5 \mathrm{~kg}$ vs. $69.4 \pm 8.3 \mathrm{~kg} ; \mathrm{p}=0.04)$, there were no differences in terms of other demographic variables. In the LSPnVAF subjects there was a greater frequency of diabetes mellitus in the recurrence group (34 vs. $13 \% ; p=0.02$ ) and also there were no differences in terms of other variables as shown in Table 1.

The subjects of PnVAF with AF recurrence showed lower velocity of left atrial appendage $(18.3 \pm 4.3 \mathrm{vs}$. $22.1 \pm 5.5 \mathrm{~cm} / \mathrm{s}$ ), but there were no differences in left atrial diameters, volumes and area. In the LSPnVAF group the subjects with AF recurrence showed greater anteroposterior $(45.9 \pm 5.6$ vs. $42.5 \pm 5.8 \mathrm{~mm} ; \mathrm{p}<0.01)$, and cephalocaudal diameter $(62.7 \pm 7.1$ vs. $50.9 \pm 8.3 \mathrm{~mm}$; $\mathrm{p}<0.001)$, left atrial volume $(73.1 \pm 20.6$ vs. $57.2 \pm$ $21.2 \mathrm{ml} ; \mathrm{p}=0.001)$, indexed volume $(41.1 \pm 14.2$ vs. 32.4 $\left.\pm 12.1 \mathrm{ml} / \mathrm{m}^{2} ; \mathrm{p}<0.01\right)$ and area $(25.7 \pm 6.6$ vs. $21.6 \pm$ $\left.5.9 \mathrm{~cm}^{2} ; \mathrm{p}<0.01\right)$, but lower velocity of the left atrial

Table 1 Demographic characteristics of the subjects

\begin{tabular}{|c|c|c|c|c|c|c|c|c|}
\hline & \multicolumn{4}{|c|}{$\operatorname{PnVAF}(\mathrm{n}=50)$} & \multicolumn{4}{|c|}{$\operatorname{LSPnVAF}(\mathrm{n}=81)$} \\
\hline & $\begin{array}{l}\text { Total } \\
(\mathrm{n}=50)\end{array}$ & $\begin{array}{l}\text { Sinus rhythm } \\
(\mathrm{n}=16)\end{array}$ & $\begin{array}{l}\text { AF recurrence } \\
(\mathrm{n}=34)\end{array}$ & $\mathrm{p}$ value* & $\begin{array}{l}\text { Total } \\
(\mathrm{n}=81)\end{array}$ & $\begin{array}{l}\text { Sinus rhythm } \\
(\mathrm{n}=38)\end{array}$ & $\begin{array}{l}\text { AF recurrence } \\
(\mathrm{n}=43)\end{array}$ & $\mathrm{p}$ value* \\
\hline Female, n (\%) & $18(36)$ & $6(38)$ & $12(35)$ & 0.88 & $37(46)$ & $20(52)$ & $17(39)$ & 0.23 \\
\hline Age (years) & $68.4 \pm 10.2$ & $69.6 \pm 8.9$ & $67.9 \pm 10.9$ & 0.57 & $66.5 \pm 13.1$ & $63.7 \pm 14.9$ & $69.0 \pm 10.9$ & 0.12 \\
\hline Weight (kg) & $73.5 \pm 10.2$ & $69.4 \pm 8.3$ & $75.5 \pm 10.5$ & 0.04 & $76.0 \pm 11.5$ & $75.0 \pm 10.6$ & $76.8 \pm 12.3$ & 0.47 \\
\hline Height (m) & $1.60 \pm 0.09$ & $1.59 \pm 0.09$ & $1.61 \pm 0.08$ & 0.55 & $1.62 \pm 0.09$ & $1.62 \pm 0.08$ & $1.62 \pm 0.10$ & 0.93 \\
\hline $\operatorname{BSA}\left(\mathrm{m}^{2}\right)$ & $1.79 \pm 0.15$ & $1.74 \pm 0.13$ & $1.82 \pm 0.16$ & 0.09 & $1.83 \pm 0.18$ & $1.81 \pm 0.16$ & $1.84 \pm 0.20$ & 0.49 \\
\hline BMI $\left(\mathrm{kg} / \mathrm{m}^{2}\right)$ & $28.5 \pm 3.9$ & $27.4 \pm 4.3$ & $29 \pm 3.6$ & 0.16 & $28.6 \pm 3.2$ & $28.4 \pm 3.5$ & $28.8 \pm 2.9$ & 0.63 \\
\hline $\begin{array}{l}\text { AF lasted } \\
\text { (months) }\end{array}$ & $6(3-11)$ & $5(3-11)$ & $6(3-11)$ & 0.20 & $18(13-120)$ & $18(13-120)$ & $18(13-120)$ & 0.58 \\
\hline Diabetes, n (\%) & $14(28)$ & $4(25)$ & $10(29)$ & 0.74 & $20(25)$ & $5(13)$ & $15(34)$ & 0.02 \\
\hline $\begin{array}{l}\text { Hypertension, } \\
\mathrm{n}(\%)\end{array}$ & $47(94)$ & $14(87)$ & $33(97)$ & 0.23 & $68(84)$ & $30(79)$ & $38(89)$ & 0.24 \\
\hline Smokers, n (\%) & $17(34)$ & $5(31)$ & $12(35)$ & 0.77 & $29(36)$ & $16(42)$ & $13(30)$ & 0.26 \\
\hline $\begin{array}{l}\text { Dyslipidemia, } \\
\mathrm{n}(\%)\end{array}$ & $9(18)$ & $3(19)$ & $6(18)$ & 0.92 & $18(22)$ & $12(32)$ & $6(14)$ & 0.06 \\
\hline ACEI, n (\%) & $17(34)$ & $6(38)$ & $11(32)$ & 0.72 & $33(41)$ & $15(39)$ & $18(42)$ & 0.82 \\
\hline ARBs, n (\%) & $18(36)$ & $4(25)$ & $14(41)$ & 0.26 & $30(37)$ & $15(39)$ & $15(35)$ & 0.66 \\
\hline $\begin{array}{l}\text { Spironolactone, } \\
\mathrm{n}(\%)\end{array}$ & $5(10)$ & $1(6)$ & $4(12)$ & 0.55 & $10(12)$ & $5(13)$ & $5(12)$ & 0.83 \\
\hline Statins, n (\%) & $10(20)$ & $3(19)$ & $7(21)$ & 0.88 & $19(23)$ & $11(29)$ & $8(19)$ & 0.27 \\
\hline
\end{tabular}

The continuous variables were described according to their distribution (mean \pm standard deviation, mean and range) while the qualitative ones were expressed as frequencies and percentages

PnVAF persistent non-valvular atrial fibrillation, $L S P n V A F$ long standing persistent non-valvular atrial fibrillation, $A F$ atrial fibrillation, $B S A$ body surface area, $B M I$ body mass index, $A C E I$ angiotensin-converting enzyme inhibitors, $A R B s$ angiotensin II receptor blockers

*Chi squared, Fisher's exact test, Student's $t$ test or U Mann-Whitney according to their distribution 
appendage $(18.3 \pm 3.9$ vs. $21.8 \pm 5.5 \mathrm{~cm} / \mathrm{s} ; \mathrm{p}<0.01)$ when compared to the sinus rhythm subjects as shown in Table 2.

No differences were observed in the measurements of ventricular parameters between subjects with $\mathrm{AF}$ recurrence versus sinus rhythm both in subjects with PnVAF and in those with LSPnVAF (see Table 3).

Regarding the diastolic function, when compared to the sinus rhythm subjects, the group with AF recurrence in PnVAF showed greater E-wave velocity $(106.5 \pm 21.3$ vs. $85.4 \pm 18.4 \mathrm{~cm} / \mathrm{s} ; \mathrm{p}=0.001)$; we observed no differences in DT, IVRT, S-wave velocity, E/e' ratio and PASP. In the LSPnVAF the group of AF recurrence showed greater E-wave velocity $(95.7 \pm 20.1$ vs. $85.4 \pm 18.9 \mathrm{~cm} / \mathrm{s} ; \mathrm{p}=0.02)$, E/e' ratio $(12.9 \pm 3.7$ vs. $10.9 \pm 2.7 ; \mathrm{p}<0.01)$ and PASP $(39.2 \pm$ 6.3 vs. $35.9 \pm 6.5 \mathrm{~mm} \mathrm{Hg} ; \mathrm{p}=0.02)$ vs those in sinus rhythm and we observed no differences in DT, IVRT and S-wave velocity by mitral annulus Doppler tissue (see Table 4).

The GPALS was $12.1 \pm 4.5 \%$ in the subjects with PnVAF and $13.6 \pm 8.7 \%$ in subjects with LSPnVAF ( $\mathrm{p}=$ ns). GPALS quantification showed good reproducibility: intraclass correlation coefficient 0.95 (95\% CI 0.83-0.99, p $<0.001$ ) and 0.92 (95\% CI 0.88-0.98, p < 0.001) for intraobserver and interobserver, respectively.

Figure 2 shows that the subjects with recurrence in PnVAF had a lower GPALS $7.8 \pm 2.0 \%$ vs. $21.2 \pm 8.9 \%$ (p $<0.001$ ) and the same phenomenon was observed in LSPnVAF with GPALS $7.3 \pm 2.7 \%$ versus $20.7 \pm 7.6 \%$ in AF recurrence vs sinus rhythm respectively $(\mathrm{p}<0.001)$.

According to the Youden index ( $\mathrm{J})$ in the ROC curve of the GPALS for recurrence risk, we obtained a cut value of $\leq 10.75 \%$, sensitivity $85 \%$, specificity $99 \%$, positive

Table 2 Echocardiographic characteristics of the left atrium

\begin{tabular}{|c|c|c|c|c|c|c|c|c|}
\hline & \multicolumn{4}{|c|}{$\operatorname{PnVAF}(\mathrm{n}=50)$} & \multicolumn{4}{|c|}{$\operatorname{LSPnVAF}(\mathrm{n}=81)$} \\
\hline & $\begin{array}{l}\text { Total } \\
(\mathrm{n}=50)\end{array}$ & $\begin{array}{l}\text { Sinus rhythm } \\
(\mathrm{n}=16)\end{array}$ & $\begin{array}{l}\text { AF recurrence } \\
(\mathrm{n}=34)\end{array}$ & $\mathrm{p}$ value $*$ & $\begin{array}{l}\text { Total } \\
(\mathrm{n}=81)\end{array}$ & $\begin{array}{l}\text { Sinus rhythm } \\
(\mathrm{n}=38)\end{array}$ & $\begin{array}{l}\text { AF recurrence } \\
(\mathrm{n}=43)\end{array}$ & $\mathrm{p}$ value $*$ \\
\hline APD (mm) & $47 \pm 5.3$ & $46.8 \pm 6.0$ & $47.0 \pm 5.1$ & 0.86 & $44.3 \pm 5.9$ & $42.5 \pm 5.8$ & $45.9 \pm 5.6$ & $<0.01$ \\
\hline $\mathrm{CCD}(\mathrm{mm})$ & $58.0 \pm 9.9$ & $54.6 \pm 10.6$ & $59.6 \pm 9.2$ & 0.09 & $56.8 \pm 9.5$ & $50.9 \pm 8.3$ & $62 \pm 7.1$ & $<0.001$ \\
\hline MLD (mm) & $44.9 \pm 8.5$ & $45.0 \pm 9.1$ & $44.8 \pm 8.3$ & 0.96 & $40.2 \pm 7.4$ & $38.6 \pm 8.1$ & $41.6 \pm 6.6$ & 0.06 \\
\hline $\mathrm{AV}(\mathrm{ml})$ & $76.0 \pm 24.0$ & $79.6 \pm 28.7$ & $74.2 \pm 21.6$ & 0.46 & $65.6 \pm 22.2$ & $57.2 \pm 21.2$ & $73.1 \pm 20.6$ & 0.001 \\
\hline $\mathrm{iAV}\left(\mathrm{ml} / \mathrm{m}^{2}\right)$ & $42.7 \pm 12.9$ & $46.4 \pm 14.9$ & $41.0 \pm 11.7$ & 0.17 & $37.0 \pm 13.9$ & $32.4 \pm 12.1$ & $41.1 \pm 14.2$ & $<0.01$ \\
\hline $\mathrm{AA}\left(\mathrm{cm}^{2}\right)$ & $28.5 \pm 9.3$ & $30.3 \pm 10.9$ & $27.7 \pm 8.5$ & 0.35 & $23.8 \pm 6.6$ & $21.6 \pm 5.9$ & $25.7 \pm 6.6$ & $<0.01$ \\
\hline $\operatorname{AAV}(\mathrm{cm} / \mathrm{s})$ & $19.5 \pm 5.0$ & $22.1 \pm 5.5$ & $18.3 \pm 4.3$ & 0.01 & $19.9 \pm 5.0$ & $21.8 \pm 5.5$ & $18.3 \pm 3.9$ & $<0.01$ \\
\hline
\end{tabular}

The continuous variables were described as mean \pm standard deviation. PnVAF persistent non valvular atrial fibrillation, $L S P n V A F$ long standing persistent non-valvular atrial fibrillation, $A P D$ antero-posterior diameter, $C C D$ cephalocaudal diameter, $M L D$ medio-lateral diameter, $A V$ atrial volume, $i A V$ indexed atrial volume, $A A$ atrial area, $A A V$ atrial appendage velocity

* Student's $t$ test

Table 3 Left ventricular echocardiographic characteristics

\begin{tabular}{|c|c|c|c|c|c|c|c|c|}
\hline & \multicolumn{4}{|c|}{$\operatorname{PnVAF}(\mathrm{n}=50)$} & \multicolumn{4}{|c|}{$\operatorname{LSPnVAF}(\mathrm{n}=81)$} \\
\hline & $\begin{array}{l}\text { Total } \\
(\mathrm{n}=50)\end{array}$ & $\begin{array}{l}\text { Sinus } \\
\text { Rhythm } \\
(n=16)\end{array}$ & $\begin{array}{l}\text { AF Recurrence } \\
(\mathrm{n}=34)\end{array}$ & $\mathrm{p}$ value $*$ & $\begin{array}{l}\text { Total } \\
(\mathrm{n}=81)\end{array}$ & $\begin{array}{l}\text { Sinus Rhythm } \\
(\mathrm{n}=38)\end{array}$ & $\begin{array}{l}\text { AF recurrence } \\
(\mathrm{n}=43)\end{array}$ & $\mathrm{p}$ value $*$ \\
\hline LVEDD (mm) & $45.8 \pm 4.6$ & $45 \pm 4.6$ & $46.1 \pm 4.6$ & 0.41 & $44.7 \pm 4.3$ & $44.9 \pm 3.9$ & $44.5 \pm 4.6$ & 0.63 \\
\hline LVESD (mm) & $28.6 \pm 4.4$ & $28.7 \pm 5.2$ & $28.8 \pm 4.1$ & 0.64 & $28.2 \pm 4.6$ & $28.2 \pm 4.1$ & $28.2 \pm 5.0$ & 0.96 \\
\hline $\mathrm{ST}(\mathrm{mm})$ & $12.6 \pm 1.3$ & $12.6 \pm 1.5$ & $12.7 \pm 1.2$ & 0.84 & $11.9 \pm 1.3$ & $11.6 \pm 1.5$ & $12.1 \pm 1.1$ & 0.11 \\
\hline PWT (mm) & $12.4 \pm 1.4$ & $12.3 \pm 1.5$ & $12.4 \pm 1.3$ & 0.93 & $11.6 \pm 1.5$ & $11.2 \pm 1.6$ & $11.9 \pm 1.2$ & 0.07 \\
\hline LVSV (ml) & $31.1 \pm 10.1$ & $32 \pm 12.3$ & $30.7 \pm 9.1$ & 0.69 & $31.5 \pm 11.5$ & $31.1 \pm 10.2$ & $31.9 \pm 12.6$ & 0.77 \\
\hline $\mathrm{EF}(\%)$ & $67.4 \pm 5.7$ & $67 \pm 6.7$ & $67 \pm 5.3$ & 0.76 & $66.2 \pm 6.4$ & $65.8 \pm 6.4$ & $66.5 \pm 6.5$ & 0.63 \\
\hline
\end{tabular}

The continuous variables were described as mean \pm standard deviation

$P n V A F$ persistent non-valvular atrial fibrillation, $L S P n V A F$ long standing persistent non-valvular atrial fibrillation; $L V E D D$, left ventricular end diastolic diameter, $L V E S D$ left ventricular end systolic diameter, $S T$ septal thickness, $P W T$ posterior wall thickness, $L V S V$ left ventricular systolic volume, $E F$ ejection fraction

*Student's $t$ test 
Table 4 Echocardiographic characteristics by Doppler

\begin{tabular}{|c|c|c|c|c|c|c|c|c|}
\hline & \multicolumn{4}{|c|}{$\operatorname{PnVAF}(\mathrm{n}=50)$} & \multicolumn{4}{|c|}{$\operatorname{LSPnVAF}(\mathrm{n}=81)$} \\
\hline & Total $(\mathrm{n}=50)$ & $\begin{array}{l}\text { Sinus rhythm (n } \\
=16)\end{array}$ & $\begin{array}{l}\text { AF recurrence } \\
(\mathrm{n}=34)\end{array}$ & $\mathrm{p}$ value $*$ & Total $(\mathrm{n}=81)$ & $\begin{array}{l}\text { Sinus rhythm (n } \\
=38)\end{array}$ & $\begin{array}{l}\text { AF recurrence } \\
(\mathrm{n}=43)\end{array}$ & $\mathrm{p}$ value* \\
\hline $\mathrm{E}(\mathrm{cm} / \mathrm{s})$ & $99.7 \pm 22.5$ & $85.4 \pm 18.4$ & $106.5 \pm 21.3$ & 0.001 & $90.9 \pm 20.1$ & $85.4 \pm 18.9$ & $95.7 \pm 20.1$ & 0.02 \\
\hline DT (ms) & $228.6 \pm 62.5$ & $232.8 \pm 70.4$ & $226.6 \pm 59.5$ & 0.74 & $215.5 \pm 56.4$ & $222.4 \pm 58.4$ & $209.5 \pm 54.5$ & 0.30 \\
\hline IVRT (ms) & $117.1 \pm 17.9$ & $123.3 \pm 14.6$ & $114.1 \pm 18.8$ & 0.09 & $111.2 \pm 18.3$ & $110.5 \pm 17.8$ & $111.9 \pm 19$ & 0.73 \\
\hline $\mathrm{S}(\mathrm{cm} / \mathrm{s})$ & $6.4 \pm 1.0$ & $6.3 \pm 0.9$ & $6.4 \pm 1.1$ & 0.78 & $7.2 \pm 2.0$ & $7.4 \pm 2.1$ & $7.1 \pm 1.9$ & 0.42 \\
\hline $\mathrm{E} / \mathrm{e}^{\prime}$ ratio & $13.6 \pm 4.3$ & $11.9 \pm 3.1$ & $14.4 \pm 4.7$ & 0.05 & $12.0 \pm 3.4$ & $10.9 \pm 2.7$ & $12.9 \pm 3.7$ & $<0.01$ \\
\hline PASP (mm Hg) & $37.5 \pm 5.8$ & $36.5 \pm 4.5$ & $38.0 \pm 6.3$ & 0.38 & $37.7 \pm 6.6$ & $35.9 \pm 6.5$ & $39.2 \pm 6.3$ & 0.02 \\
\hline
\end{tabular}

The continuous variables were described as mean \pm standard deviation

PnVAF persistent non-valvular atrial fibrillation, $L S P n V A F$ long standing persistent non-valvular atrial fibrillation, $L V E D D$ left ventricular end diastolic diameter, $L V E S D$ left ventricular end systolic diameter, $E \mathrm{E}$ wave, $D T$ deceleration time, $I V R T$ isovolumetric relaxation time, $S \mathrm{~S}$ wave velocity, $E / E$ ' ratio $\mathrm{E}$ velocity to e' velocity ratio, $P A S P$ pulmonary artery systolic pressure

*Student's $t$ test or U Mann-Whitney according to their distribution

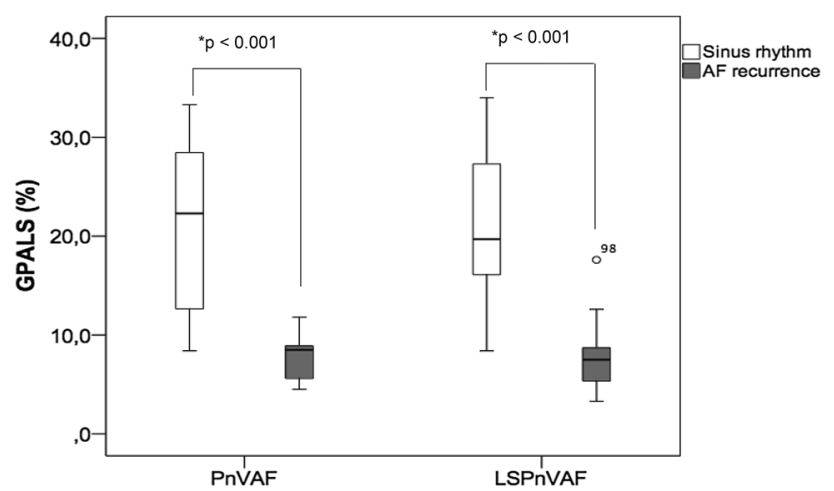

Fig. 2 Atrial deformation according to the presence or absence of recurrence after cardioversion, GPALS is lower in subjects with recurrence versus subjects who remained in sinus rhythm in both groups of AF. *U Mann-Whitney. GPALS global peak atrial longitudinal strain, PnVAF persistent non-valvular AF, LSPnVAF long standing persistent non-valvular $\mathrm{AF}$

predictive value $85 \%$, negative predictive value $90 \%$, and finally a LR+ 8.5, and LR- 0.17 (Fig. 3). The multivariate Cox proportional hazards regression analysis included the following variables: age, diabetes mellitus, weight, atrial diameters, volumes, area, velocity of left atrial appendage, E-wave velocity, E/e' ratio and GPALS. For the PnVAF group only GPALS $\leq 10.75 \%$ HR 8.89 [(2.2-35.7), $\mathrm{p}<$ $0.01]$ remains as independent predictor of $\mathrm{AF}$ recurrence at 6 months; for LSPnVAF group only age HR 1.039 [(1.007-1.071), $\mathrm{p}=0.01]$, and GPALS $\leq 10.75 \%$ HR 28.1 [(7.2-109.1), $\mathrm{p}<0.001]$, remains as independent predictors of AF recurrence at 6 months. The event-free survival curve (Fig. 4) showed that the GPALS $\leq 10.75 \%$ cut-point discriminates subjects with sinus rhythm vs those with recurrence at 180-day follow-up in PnVAF and LSPnVAF $(\mathrm{p}<0.001)$.

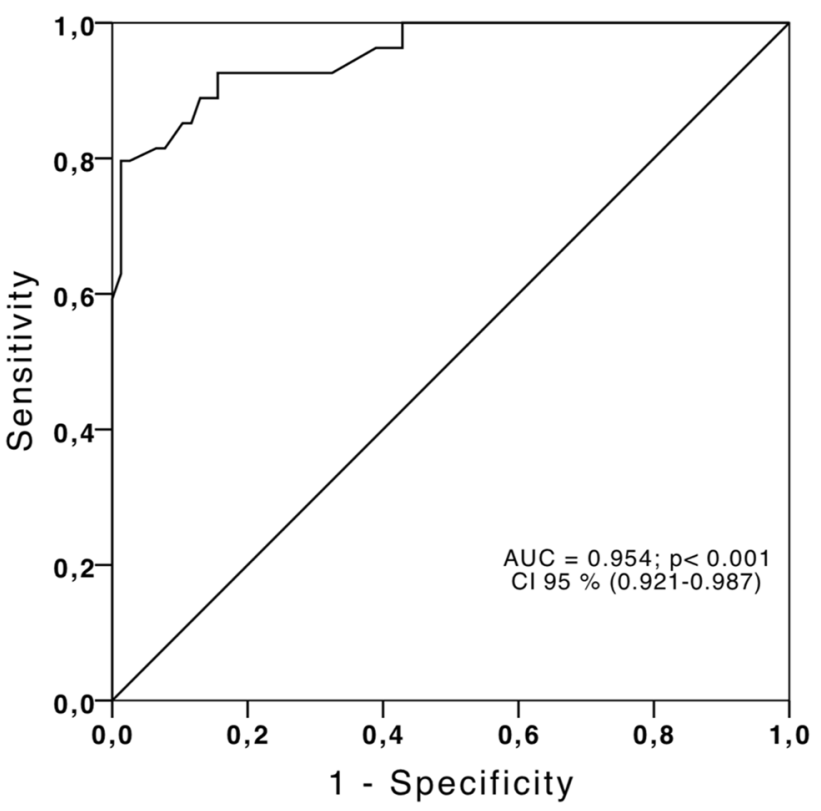

Fig. 3 ROC curve for GPALS and risk of recurrence after cardioversion in subjects with PnVAF and LSPnVAF. A cut-point of GPALS $\leq 10.75 \%$ identifies recurrence with S $85 \%$, E 99\%, PPV 85\%, NPV 90\%, LR+ 8.5 and LR- 0.17. GPALS global peak atrial longitudinal strain, PnVAF persistent non-valvular AF, LSPnVAF long standing persistent non-valvular AF, $P P V$ positive predictive value, $N P V$ negative predictive value, $L R+$ positive likelihood ratio, $L R-$ negative likelihood ratio

\section{Discussion}

Nowadays, there is a marked tendency to choose the rhythm control strategy in subjects with symptomatic AF through cardioversion or treatments like ablation. There currently are few studies that include subjects with 


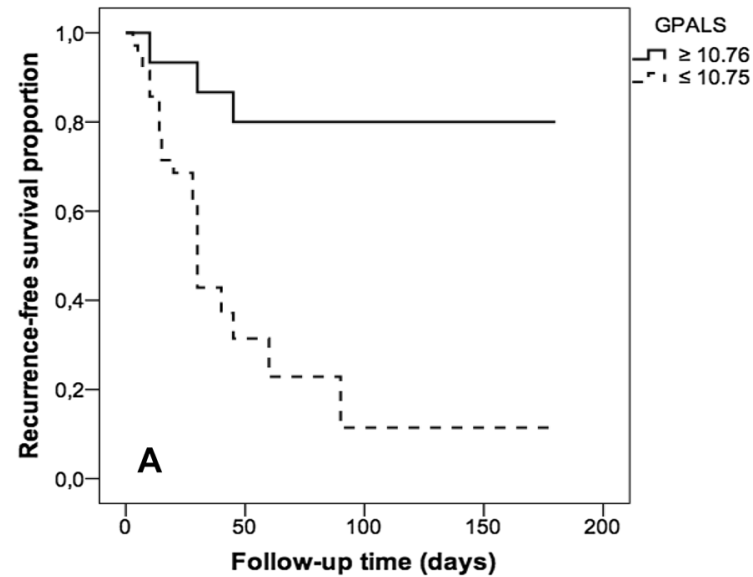

Fig. 4 Recurrence-free survival curve of subjects with PnVAF (a) and LSPnVAF (b) according to the GPALS cut-point obtained by Youden index. The subjects with GPALS $\leq 10.75 \%$ have greater

LSPnVAF [8-14]. Cardioversion brings benefits such as: organization of the atrial activation/contraction and a sequence of normal atrioventricular activation, contribution to atrial contraction with $25-30 \%$ of cardiac output, proper functioning of the atrioventricular valves, embolism risk reduction, and reversal remodeling [11]. Nevertheless, there still exists controversy when defining who the best candidates for elective cardioversion are since up to $60 \%$ of recurrence [24] has been reported, a fact which is consistent with the findings in this study.

Reports in the literature establish as predictors of recurrence factors such as: age, absence of treatment with antiarrhythmic drugs, use of ACE inhibitors, ARBs and spironolactone; evolution time of arrhythmia, chronic pneumopathy, left atrial diameter $>40 \mathrm{~mm}$, appendage ejection fraction $<$ $30 \%$, appendage emptying flow velocity, and indexed atrial volume, among others [24-33]. In a population of subjects with non-valvular AF, Ahmed et al. [34] found greater values of diameters and atrial volumes in subjects with recurrence. Our results are similar: the subjects with recurrence showed greater atrial diameters, areas and volumes, as well as a lower appendage velocity versus those subjects in sinus rhythm at 6 months. However, we detected no differences regarding age, anti-remodeling drugs, and evolution time of arrhythmia.

One of the proposals that explains recurrence is supported by atrial remodeling as a phenomenon of adaptive regulation with multifactor origin that conditions metabolic, functional, electrical, structural, and neurohumoral changes associated to arrhythmia maintenance and that lead to fibrosis $[15,16$, 20-22]. The conventional clinical and echocardiography predictors are associated to recurrence, but they are unable to discriminate the degree of atrial fibrosis. In this opportunity niche, speckle tracking plays a fundamental role since it

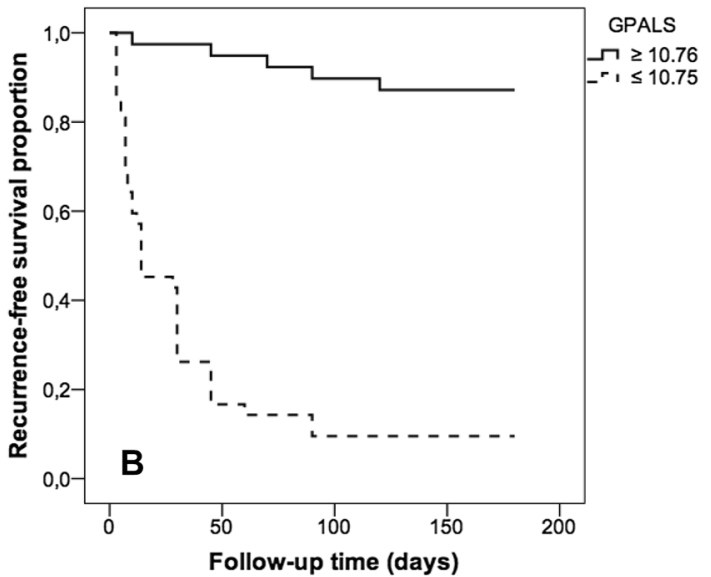

recurrence at 6 months versus subjects with GPALS $\geq 10.76 \%$. PnVAF persistent non-valvular AF, LSPnVAF long standing persistent non-valvular AF, GPALS global peak atrial longitudinal strain

allows measuring the deformation of the atrial muscle tissue and is indirectly a fibrosis surrogate marker: the greater the deformation, the lower the fibrosis and vice versa [36-42].

The literature points out that, in subjects with AF, GPALS is decreased. Kuppahally et al. [43] reported values of $27 \pm$ $15 \%$ in the medio-septal region and $35 \pm 18 \%$ in the mediolateral region, as well as an inverse correlation between the degree of fibrosis and atrial deformation $(\mathrm{r}=-0.5, \mathrm{p}$ $<0.003)$. We observed that the recruited subjects had a GPALS of $12.1 \pm 4.5 \%$ in the subjects with PnVAF and 13.6 $\pm 8.7 \%$ in subjects with LSPnVAF. This may be lower than that reported by Kuppahally et al. [43] since we reported the value of global deformation and only included subjects with non-valvular AF and arrhythmia of longer duration.

Dell'Era et al. [45] studied a group of 130 subjects with persistent $\mathrm{AF}$ who were taken to electrical cardioversion; 1 month after follow-up, there was $44 \%$ of recurrence. In the patients with recurrence, the researchers found a GPALS of $11.36 \pm 5.19$ versus $17.15 \pm 7.5 \%$ in the sinus group $(\mathrm{p}<$ $0.001)$. We found a GPALS of $7.8 \pm 2.0 \%$ vs. $21.2 \pm 8.9 \%$ $(\mathrm{p}<0.001)$ in subjects with PnVAF and GPALS $7.3 \pm 2.7$ versus $20.7 \pm 7.6(p<0.001)$ in LSPnVAF when comparing $\mathrm{AF}$ recurrence vs sinus rhythm respectively. The differences found in the GPALS determination between Dell'Era et al. [45] and our study may be due to the fact that the AF duration in the patients included in this study was greater while the AF was of non-valvular etiology.

Motoki et al. [46] reported that a group of subjects with persistent and paroxysmal AF of multiple etiologies treated with transcatheter ablation had $42 \%$ of recurrence at 8-month follow-up. Using the GPALS cut-point $23.2 \%$, they predicted arrhythmia recurrence with sensivity of $76 \%$ and specificity of $66 \%$. In subjects with non-valvular AF taken to elective electrical cardioversion, we found that a GPALS cut-point 
$\leq 10.75 \%$ has $85 \%$ of sensitivity, $99 \%$ of specificity, $85 \%$ PPV, $90 \%$ NPV, LR+ 8.5 and LR- 0.17 . We also found that this cut-point allows identifying recurrence risk at 6 months with HR 8.89 [(2.2-35.7), $\mathrm{p}<0.01]$ for PnVAF and HR 28.1 [(7.2-109.1), $\mathrm{p}<0.001]$ for LSPnVAF. The cut-point detected in our population is slightly lower than the one reported by Motoki et al. [46]. This is probably due to the selection criteria given the fact that we included subjects with non-valvular AF whose evolution time has an ample range; this situation probably favored a greater remodeling and fibrosis.

It is important to say that, in the subjects with arrhythmia recurrence, we observed no differences according to the type of AF (PnVAF vs. LSPnVAF) in terms of diameters, areas and atrial volumes, diastolic function parameters or atrial deformation values. This is consistent with the reports found in literature because these subjects supposedly have greater fibrosis, something that is evident in their values of GPALS 7.8 versus $7.3 \%(\mathrm{p}=\mathrm{ns})$, respectively. In contrast, in the group of subjects that remained in sinus rhythm at six months, the ones with PnVAF showed greater diameters, areas and atrial volumes when compared with the subjects with LSPnVAF. This finding suggests that the atria of patients with AF of shorter evolution time are more compliant due to a lower degree of fibrosis, considering the difference in the GPALS values. Even though there is a tendency among the subjects with persistent AF to have more deformation, we did not detect a significant statistical difference due to the sample size of recruited subjects.

Taking into account the reference framework laid by Kuppahally et al. [43] and Cameli et al. [44], we can infer that our results suggest that the patients with recurrence have a greater degree of atrial fibrosis (remodeling) evidenced by the reduction in the GPALS as a surrogate marker. This fact is closely related to the physiopathology reported in literature as part of the genesis and maintenance of arrhythmia when creating multiple reentry circuits or depolarization fronts that undergo fractionation $[47,48]$.

We consider that one of the limitations our study has is that the duration of the arrhythmia was determined according to the information provided by the participants of the study, since there is currently no method that allows defining the exact time the arrhythmia started with precision. Therefore, it might be possible that some patients were not properly classified. Nevertheless, the cut-point of GPALS $\leq$ $10.75 \%$ predicts recurrence in the analysis of all the subjects and in the analysis by AF group.

\section{Conclusions}

In subjects with PnVAF and LSPnVAF taken to elective cardioversion, a cut-point of the GPALS $\leq 10.75 \%$ predicts arrhythmia recurrence at 6 months after electrical cardioversion.
Acknowledgements We thank Betty Lou Chinn RN for their expertise and assistance in language editing of the manuscript.

\section{Compliance with ethical standards}

Conflict of interest All authors declare that they have no conflict of interest.

Open Access This article is distributed under the terms of the Creative Commons Attribution 4.0 International License (http://creativeco mmons.org/licenses/by/4.0/), which permits unrestricted use, distribution, and reproduction in any medium, provided you give appropriate credit to the original author(s) and the source, provide a link to the Creative Commons license, and indicate if changes were made.

\section{References}

1. Camm AJ, Kirchhof P, Lip GYH, Schotten U, Savelieva I, Ernst S, Van Gelder I, Al-Attar N, Hindricks G, Prendergast B, Heidbuchel H, Afieri O, Angelini A, Atar D, Colonna P, De Caterina R, De Sutter J, Goette A, Gorenek B, Heldal M, Hohloser SH, Kolh P, Le Heuzey JY, Ponikowski P, Rutten FH, ESC Committee for Practice Guidelines (2010) Guidelines for the management of atrial fibrillation: the Task Force for the Management of Atrial Fibrillation of the European Society of Cardiology (ESC). Eur Heart J 31:2369-2429. https://doi.org/10.1093/eurheartj/ehq278

2. Khaykin Y, Shamiss Y (2012) Costs considerations in the management of atrial fibrillation-impact of dronedarone. Clinicoecon Outcomes Res 4:67-68. https://doi.org/10.2147/CEOR.S16675

3. Olivotto I, Cecchi F, Casey SA, Dolara A, Traverse JH, Maron BJ (2001) Impact of atrial fibrillation on the clinical course of hypertrophic cardiomyopathy. Circulation 104:2517-2524. https ://doi.org/10.1161/hc4601.097997

4. Wolf PA, Mitchell JB, Baker CS, Kannel WB, D'Agostino RB (1998) Impact of atrial fibrillation on mortality, stroke, and medical costs. Arch Intern Med 158:229-234. https://doi.org/10.1001/ archinte.158.3.229

5. Benjamin EJ, Wolf PA, D'Agostino RB, Silbershatz H, Kannel WB, Levy D (1998) Impact of atrial fibrillation on the risk of death: the Framingham Heart Study. Circulation 98:946-952. https://doi.org/10.1161/01.CIR.98.10.946

6. Ringborg A, Nieuwlaat R, Lindgren P, Jönsson B, Fidan D, Maggioni A, Lopez-Sendon J, Stepinska J, Cokkinos DV, Crijns HJGM (2008) Costs of atrial fibrillation in five European countries: results from the Euro Heart Survey on atrial fibrillation. Europace 10:403-411. https://doi.org/10.1093/europace/eun048

7. Wolowacz SE, Samuel M, Brennan VK, Jasso-Mosqueda JG, Van Gelder IC (2011) The cost of illness of atrial fibrillation: a systematic review of the recent literature. Europace 13:1375-1385. https://doi.org/10.1093/europace/eur194

8. Guía de práctica clínica, diagnóstico y tratamiento de la fibrilación auricular (2012) México: Secretaría de Salud. Rev Med Inst Mex Seguro Soc 50:213-231

9. January CT, Wann S, Alpert JS, Calkins H, Cleveland JC, Cigarroa JE, Conti JB, Ellinor PT, Ezekowitz MD, Field ME, Murray KT, Sacco RL, Stevenson WG, Tchou PJ, Tracy CM, Yancy CW (2014) AHA/SCC/HRS Guideline for the management of patients with atrial fibrillation. A report of the American College of Cardiology Foundation/American Heart Association Task Force on Practice Guidelines. J Am Coll Cardiol 64:2246-2280. https://doi. org/10.1016/j.jacc.2014.03.021 
10. Fuster V, Rydén LE, Cannom DS, Crijns HJ, Curtis AB, Ellenbogen KA, Halperin JL, Kay GN, Le Huezey JY, Lowe JE, Olsson SB, Prystowsky EN, Tamargo JL, Wann LS (2011) ACCF/ AHA/HRS focused updates incorporated into the ACC/AHA/ ESC 2006 guidelines for the management of patients with atrial fibrillation: a report of the American College of Cardiology Foundation/American Heart Association Task Force on Practice Guidelines developed in partnership wit the European Society of Cardiology and in collaboration with the European Heart Rhythm Association and the Heart Rhythm Society. J Am Coll Cardiol 57:e101-e198. https://doi.org/10.1016/j. jacc.2010.09.13

11. Camm AJ, Savelieva I (2012) Atrial fibrillation: the rate versus the rhythm management controversy. J R Coll Phys Edinb 42:23-34. https://doi.org/10.4997/jrcpe.2012.s03

12. Kato T, Yamashita T, Sagara K, Iinuma H, Fu LT (2004) Progressive nature of paroxysmal atrial fibrillation. Observations of 14-year follow up study. Circ J 68:568-572. https://doi. org/10.1253/circj.68.568

13. Moreno-Ruíz LA, Rodríguez-Piña H, Martínez-Enríquez JE (2012) Fibrilación auricular. Evaluación y tratamiento. Rev Med Inst Mex Seguro Soc 50:273-284

14. Sopher SM, Camm AJ (1996) Atrial fibrillation: maintenance sinus rhythm versus rate control. Am J Cardiol 77:24A-37A. https ://doi.org/10.1016/S0002-9149(97)89115-1

15. Casaclang-Verzosa G, Gersh BJ, Tsang TSM (2008) Structural and functional remodeling of the left atrium. Clinical and therapeutic implications for atrial fibrillation. J Am Coll Cardiol 51:1-11

16. Nattel S (1999) Electrophysiologic remodeling: are ion channels static players or dynamic movers? J Cardiovasc Electrophysiol 10:1553-1556. https://doi.org/10.1111/j.1540-8167.1999.tb002 14. $\mathrm{x}$

17. Goette A, Honeycutt C, Langberg JJ (1996) Electrical remodeling in atrial fibrillation. Time course and mechanisms. Circulation 94:2968-2974. https://doi.org/10.1161/01.CIR.94.11.2968

18. Ausma J, Litjens N, Lenders MH, Duimel H, Mast F, Wouters L, Ramaekers F, Allesie M, Borgers M (2001) Time course of atrial fibrillation-induced cellular structural remodeling in atria of the goat. J Mol Cell Cardiol 33:2083-2094. https://doi.org/10.1006/ jmcc. 2001.1472

19. Li DS, Fareh S, Leung TK, Nattel S (1999) Promotion of atrial fibrillation by heart failure in dogs-atrial remodeling of a different sort. Circulation 100:87-95. https://doi.org/10.1161/01. CIR.100.1.87

20. Burstein B, Nattel S (2008) Atrial fibrosis: mechanisms and clinical relevance in atrial fibrillation. J Am Coll Cardiol 51:802-809. https://doi.org/10.1016/j.jacc.2007.09.064

21. Everett TH, Olgin JE (2007) Atrial fibrosis and the mechanisms of atrial fibrillation. Heart Rhythm 4:S24-S27. https://doi. org/10.1016/j.hrthm.2006.12.040

22. Tan AY, Zimetbaum P (2011) Atrial fibrillation and atrial fibrosis. J Cardiovasc Pharmacol 57:373-375. https://doi.org/10.1097/ FJC.0b013e3182073c78

23. Shelton RJ, Kaye GC, Cleland JGF (2004) Controlling persistent atrial fibrillation. QJM 97:179-180. https://doi.org/10.1093/qjmed /hch033

24. Kim SK, Pak HN, Park JH, Ko KJ, Lee JS, Choi JI, Choi DH, Kim YH (2009) Clinical and serological predictors for the recurrence of atrial fibrillation after electrical cardioversion. Europace. https ://doi.org/10.1093/europace/eup321

25. Madrid AH, Bueno MG, Rebollo JMG, Marín I, Peña G, Bernal E, Rodriguez A, Cano L, Cano JM, Cabeza P, Moro C (2002) Use of irbesartan to maintain sinus rhythm in patients with long-lasting persistent atrial fibrillation a prospective and randomized study. Circulation 106:331-336. https://doi.org/10.1161/01.CIR.00000 22665.18619 .83
26. Fogari R, Mugellini A, Destro M, Corradi L, Zoppi A, Fogari E, Rinaldi A (2006) Losartan and prevention of atrial recurrence in hypertensive patients. J Cardiovasc Pharmacol 47:46-50. https:// doi.org/10.1097/01.fjc.0000193808.99773.28

27. Fogari R, Zoppi A, Maffioli P, Mugellini A, Pretti P, Perrone T (2012) Effect of telmisartan on paroxysmal atrial fibrillation recurrence in hypertensive patients with normal or increased left atrial size. Clin Cardiol 35:359-364. https://doi.org/10.1002/ clc. 21994

28. Healey JS, Baranchuk A, Crystal E, Morillo CA, Garfinkle M, Yusuf S, Connolly SJ (2005) Prevention of atrial fibrillation with angiotensin-converting enzyme inhibitors and angiotensin receptor blockers. A meta-analysis. J Am Coll Cardiol 45:1832-1839. https://doi.org/10.1016/j.jacc.2004.11.070

29. Disertori M, Barlera S, Staszewsky L, Latini R, Quintarelli S, Franzosi M (2012) Systematic review and metaanalysis: reninangiotensin system inhibitors in the prevention of atrial fibrillation recurrences: an unfulfilled hope. Cardiovasc Drugs Ther 1:47-54. https://doi.org/10.1007/s10557-011-6346-0

30. Ökçün B, Yigit Z, Küçükoglu MS, Mutlu H, Sansoy V, Güzelsoy D, Üner S (2002) Predictors for maintenance of sinus rhythm after cardioversion in patients with nonvalvular atrial fibrillation. Echocardiography 19:351-357. https://doi.org/10.104 6/j.1540-8175.2002.00351.x

31. Antonielli E, Pizzuti A, Pálinkás A, Tanga M, Gruber M, Michelassi C, Varga A, Bonzano A, Gandolfo N, Halmai L, Bassignana A, Imran MB, Deln Evo F, Csanády M, Picano E (2002) Clinical value of left atrial appendage flow for prediction of long-term sinus rhythm maintenance in patients with nonvalvular atrial fibrillation. J Am Coll Cardiol 39:1443-1449

32. Marchese P, Bursi F, Delle Donne G, Malavasi V, Casali E, Barbieri A, Melandri F, Modena MG (2011) Indexed left atrial volume predicts de recurrence of non-valvular atrial fibrillation after successful cardioversion. Eur J Echocardiogr 12:214-221. https:// doi.org/10.1093/ejechocard/jeq176

33. Marchese P, Malavasi V, Rossi L, Nikolskaya N, Delle Donne G, Becirovic M, Colantoni A, Luciani A, Modena MG (2012) Indexed left atrial volume is superior to left atrial diameter in predicting non valvular atrial fibrillation recurrence after successful cardioversion: a prospective study. Echocardiograpy 3:276-284. https://doi.org/10.1111/j.1540-8175.2011.01580.x

34. Ahmed MK, Abdelazez WF, Nasif MA (2015) Assesment of left atrium mechanical function by deformation imaging in atrial fibrillation and its correlation with CHA2DS2-Vasc risk score. Egypt Heart J 67:209-215. https://doi.org/10.1016/j. ehj.2014.08.001

35. D'Ascenzo F, Corieto A, Biondi-Zoccal G, Anselmino M, Ferraris F, Di Biase L, Natale A, Hunter RJ, Schilling RJ, Miyazaki S, Tada H, Aonuma K, Yenn-Jiang L, Tao H, Ma C, Packer D, Hammill S, Gaita F (2013) Which are the most reliable predictors of recurrence of atrial fibrillation afer transcatheter ablation?: a meta-analysis. Int J Cardiol 167:1984-1989. https://doi. org/10.1016/j.ijcard.2012.05.008

36. Blume GG, Mcleod CJ, Barnes ME, Seward JB, Pellikka PA, Bastiansen PM, Tsang TSM (2011) Left atrial function: physiology, assessment, and clinical implications. Eur J Echocardiogr 12:421-430. https://doi.org/10.1093/ejechocard/jeq175

37. Wang T, Wang M, Fung JWH, Yip GWK, Zhang Y, Ho PPY, Tse DMK, Yu CM, Sanderson JE (2007) Atrial strain echocardiography can predict success or failure of cardioversion for atrial fibrillation: a combined transthoracic tissue Doppler and transesophageal imaging study. Int J Cardiol 114:202-209. https ://doi.org/10.1016/j.ijcard.2006.01.051

38. Geyer H, Caracciolo G, Abe H, Wilansky S, Carerj S, Gentile F, Nesser HJ, Khandheria B, Narula J, Sengupta P (2010) Assesment of myocardial mechanics using speckle tracking 
echocardiography: fundamentals and clinical applications. J Am Soc Echocardiogr 23:351-369. https://doi.org/10.1016/j. echo.2010.02.015

39. Pinto M (2011) Strain: una ventana a la mecánica ventricular. Rev Chil Cardiol 31:155-159. https://doi.org/10.4067/S0718-85602 011000200009

40. Langeland S, D'hooge J, Wouters PF, Leather HA, Claus P, Bijnens B, Sutherland GR (2005) Experimental validation of a new ultrasound method for the simultaneous assessment of radial and longitudinal myocardial deformation independent of insonation angle. Circulation 112:2157-2162. https://doi.org/10.1161/ CIRCULATIONAHA.105.554006

41. Cameli M, Caputo M, Mondillo S, Ballo P, Palmerini E, Lisi M, Marino E, Galderisi M (2009) Feasibility and reference values of left atrial longitudinal strain imaging by two dimensional speckle tracking. Cardiovasc Ultrasound 7:1-6. https://doi. org/10.1186/1476-7120-7-6

42. Cameli M, Lisi M, Focardi M, Reccia R, Natali BM, Sparla S, Mondillo S (2012) Left atrial deformation analysis by speckle tracking echocardiography for prediction of cardiovascular outcomes. Am J Cardiol 110:264-269. https://doi.org/10.1016/j. amjcard.2012.03.022

43. Kuppahally SS, Akoum N, Burgon NS, Badger TJ, Kholmovski EG, Vijayakumar S, Rao SN, Blauer J, Fish EN, DiBella EVR, MacLeod RS, McGann C, Ltwin SE, Marrouche NF (2010) Left atrial strain and strain rate in patients with paroxysmal and persistent atrial fibrillation. Relationship to left atrial structural remodeling detected by delayed-enhancement MRI. Circ Cardiovasc Imaging 3:231-239. https://doi.org/10.1161/CIRCIMAGIN G.109.865683
44. Cameli M, Lisi M, Righini FM, Massoni A, Natali BM, Focardi M, T'Acchini D, Geyer A, Curci V, Di Tommaso C, Lisi G, Maccherini M, Chiavarelli M, Massetti M, Tanganeli P, Mondillo S (2013) Usefulness of atrial deformation analysis to predict left atrial fibrosis and endocardial thickness in patients undergoing mitral valve operations for severe mitral regurgitation secondary to mitral valve prolapse. Am J Cardiol 111:595-601. https://doi. org/10.1016/j. amjcard.2012.10.049

45. Dell'Era G, Rondano E, Franchi E, Marino PM (2010) Atrial asynchrony and function before and after electrical cardioversion for persistent atrial fibrillation. Eur J Echocardiogr 11:577-583. https://doi.org/10.1093/ejechocard/jeq010

46. Motoki H, Negishi K, Kusunose K, Popovic ZB, Bhagarva M, Wazni O, Saliba WI, Chung MK, Marwick TH, Klein AL (2014) Global left atrial strain in the prediction of sinus rhythm maintenance after catheter ablation for atrial fibrillation. J Am Soc Echocardiogr 27:1184-1192. https://doi.org/10.1016/j. echo.2014.08.017

47. Harada M, Van Wagoner D, Nattel S (2015) Role of inflammation in atrial fibrillation pathophysiology and management. Circ J 79:495-502. https://doi.org/10.1253/circj.CJ-15-0318

48. Hu YF, Chen YJ, Lin YJ, Chen SA (2015) Inflammation and the pathogenesis of atrial fibrillation. Nat Rev Cardiol 12:230-243. https://doi.org/10.1038/nrcardio.2015.2

Publisher's Note Springer Nature remains neutral with regard to jurisdictional claims in published maps and institutional affiliations. 